\title{
Influence of the condition of pullout holes on the surrounding ground
}

\author{
Shuichi Kuwahara', Shinya Inazumi $i^{*} \mathbb{0}$, Apiniti Jotisankasa ${ }^{3}$ and Susit Chaiprakaikeow ${ }^{3}$
}

\author{
${ }^{*}$ Correspondence: \\ inazumi@shibaura-it.ac.jp \\ ${ }^{2}$ Department of Civil \\ Engineering, Shibaura \\ Institute of Technology, \\ Tokyo, Japan \\ Full list of author information \\ is available at the end of the \\ article
}

\begin{abstract}
In recent years, removal work of existing piles has been increasing, and many pullingout methods for existing piles are being applied. As for the present situation, there is concern that the physical characteristics of the ground will deteriorate due to the holes that remain after pulling out the existing piles (pullout holes). In addition, the filler to be injected into these pullout holes has not yet been specified and the influence of the physical properties of the filler on the surrounding ground has not been elucidated. In this study, therefore, the authors evaluated the influence of pullout holes on the static physical characteristics of the ground by elasto-plastic analysis using a threedimensional static FEM. As a result, the settlement of the ground surface was seen to increase as the number of pullout holes increased, but it was obvious that the region of the surrounding ground influenced by the settlement does not depend on the number of pullout holes. The authors also clarified that the strength characteristics of the filler injected into the pullout holes do not cause local settlement of the surrounding ground and that it is important to perform reliable filling to the bottom of the pullout holes.
\end{abstract}

Keywords: Pile foundation, Pull out hole, Filler, Finite element method, Static elastoplastic analysis

\section{Introduction}

In Japan, during the period of high economic growth from 1955 to 1965, buildings and public structures, such as bridges and tunnels, were constructed in large quantities. However, it is thought that the aging of these buildings and structures will progress intensively in the near future. Also, due to the rising awareness of disaster prevention as a result of the Great East Japan Earthquake, the demand for the rebuilding of aging buildings and condominiums is also increasing. Furthermore, according to an announcement by the Ministry of Internal Affairs and Communications, it is said that 12,251 public facilities are being considered for demolition by municipalities nationwide [16]. This is also due to the decrease in the need for these facilities due to the aging population and a general decline in the population. Based on the above background, the demand for the demolition of structures is expected to increase more and more in the near future.

Many cities in Japan are located on soft ground and many structures built in these cities were constructed with pile foundations. Therefore, when trying to utilize land (as 
new land) where structures already exist, it is necessary to remove both the existing piles that have supported the existing structures as well as the existing structures themselves for the construction of new structures. Moreover, existing piles and so on that are not reusable are designated as industrial waste, and it is very difficult to leave such industrial waste in the ground. Furthermore, many troubles may be encountered during landselling transactions due to these "hidden defects" [6]. Therefore, the removal of existing piles is mandatory.

The methods for removing existing piles include pulling-out methods, methods of crushing and removing, and so on. As the methods of crushing and removing involve many controversial issues, such as vibrations, noise, and possible harm to the environment, the pulling-out methods have been widely used for removing existing piles. As one of the innovative pulling-out methods, a method to chuck the tip of existing piles has been developed and applied. In this method, the casing hugs and pulls out the entire existing piles. With this method, therefore, it is possible to more reliably pull out broken existing piles and existing piles whose joint parts are not joined than with other pullingout methods $[9,10]$.

However, in pulling-out methods, holes form when the existing piles are pulled out (hereafter, they are referred to as "pullout holes"). If these pullout holes are left as they are, it is possible that the sediment in the hollow portions will collapse and/or gaps in the ground will expand and cause the settlement of the ground. Therefore, it is necessary to stabilize the pullout holes by filler injection. Regarding the fillers for pullout holes, mountain sand and recycled sand were often used in the past because they are inexpensive and easy to inject. However, as reliable filling and stable strength cannot be ensured with these sands, the use of fluidized soil and cement bentonite has recently been increasing. Unfortunately, there are no clear provisions for utilizing these fillers, and the influence of the difference in strength and material composition among the fillers injected into the pullout holes on the deformation behavior of the ground has not been clarified. The authors believe that solving these issues of the fillers is critical to applying pulling-out methods to existing piles.

In this study, the authors perform a three-dimensional elasto-plastic analysis for cases where pullout holes are left as hollows and where filler is injected into the pullout holes. By analyzing the deformation behavior of each case analytically and comparing the results, the characteristics required for filling pullout holes are confirmed.

\section{Research trends for piles and existing piles}

Research trends in analysis methods

There have been many studies on pile foundations since ancient times, but the field management of driving and pulling out pile foundations depends on empirical knowledge. In order to solve this issue, the Finite Element Method (FEM) and the Distinct Element Method (DEM) are currently applied to evaluate pile foundations as the analytical methods. The DEM is a method for tracking the behavior of individual elements and analyzing the dynamic behavior of the aggregate, which is an aggregate of individual elements and has been widely applied to slope failures, powder movement phenomena, and so on [7]. However, because the DEM is used for analysis from the microscopic viewpoint, it 
is necessary to use a FEM capable of outputting analysis results from the macroscopic viewpoint in order to evaluate the influence of the surrounding ground.

In addition, when designing the foundations of structures, it was previously mainstream to assume the ground as a linear elastic body. However, the stress-strain relationship of the actual ground is nonlinear, and the ground stiffness decreases with increases in stress and strain. Therefore, in recent years, designs that assume the ground as a nonlinear elastic-plastic body have been gradually increasing.

\section{Evaluation of influence of pile driving on surrounding ground}

There are various kinds of pile foundations, such as $\mathrm{H}$ steel pile, cast-in-place concrete pile, ready-made concrete pile, pine cone, steel pipe pile, and columnar ground improvement foundations (Civil Engineering [3].

In terms of the pile driving, paper (Profound [13] proposed a theoretical method for estimating the bearing capacity during the pile driving and the static bearing capacity during loading that considers the construction procedure from pile driving to loading. In the analysis of the horizontal characteristics of the bearing capacity for a deep pile foundation installed on a slope, paper [14] compared field phenomena using two-dimensional and three dimensional elasto-plastic analyses using the same parameters. Furthermore, the results of these analyses showed that they can be applied to estimate the resistance to the pulling out of inclined piles, which confirms the importance of designing foundations such that the piles will not come out [11].

In addition, paper [7] used the DEM to try to visualize the behavior of a pile while being driven into the ground. By analyzing the use of the DEM in this way, it may be possible to prevent the phenomenon whereby the pile does not reach the supporting layer, which is presently one of the critical issues at construction sites.

\section{Pulling-out analysis of sheet piles}

The FEM is also used as a method to analyze the deformation behavior of the surrounding ground as well as the deformation and stress of an existing structure during the excavation of retaining sheet piles. Previously, an elastic analysis was mainly used, but now an elasto-plastic FEM is being used to predict and analyze the field behavior and to estimate the settlement of the surrounding ground during the excavation of retaining sheet piles [8]. It should be noted that a method to suppress the settlement of the surrounding ground has been developed which continuously fills the gaps created by the pulling out of the retaining sheet piles (Helical Drilling Inc. [5]. This method is similar to the method which chucks the tip of existing piles and simultaneously injects the filler while pulling out the existing piles. It is thought that methods for pulling out the retaining sheet piles and the existing piles were developed from almost the same viewpoint.

\section{Pulling-out analysis of piles in two dimensions}

Many of the previous studies evaluated the physical properties of the existing piles themselves, such as the physical durability. Only a few studies have evaluated the influence of existing piles or the pullout holes remaining after extracting existing piles on the surrounding ground. It is very new to evaluate the influence of the pullout holes on the surrounding ground and the results will be indispensable in Japan in 
the future. Previous studies have analyzed the effects of pullout holes in two dimensions (see Fig. 1). A two-dimensional elastic analysis by the FEM was carried out on a ground from which the existing piles had not been pulled out, on a ground from which the existing piles had been pulled out and the pullout holes had been left hollow, and on a ground from which the existing piles had been pulled out and the pullout holes had been filled with a filler [9]. However, an analysis in two dimensions can only account for the displacement on the $\mathrm{X}-\mathrm{Y}$ plane. The field arrangement of the piles is three-dimensional. In a two-dimensional analysis, it is not possible to consider the influence in the $\mathrm{Z}$ direction on the pullout holes such as the region of settlement and the pullout holes existing in the $\mathrm{Z}$ direction on the $\mathrm{X}-\mathrm{Y}$ plane. In addition, because the ground is an elasto-plastic body, more realistic behavior can be known by performing an elastoplastic analysis rather than an elastic analysis. In order to consider these issues, in this research, the authors decided to study the influence of pullout holes on the surrounding ground by a three-dimensional elasto-plastic analysis.

\section{Analysis method and analysis cross section}

The numerical calculations were performed using commercial software Midas GTS NX [15]. Midas GTS NX is a FEM based modeling software. It includes CAD based 2D and 3D commands for modeling. GTS NX analyses foundation stability subjected to lateral pressure and differential settlements.

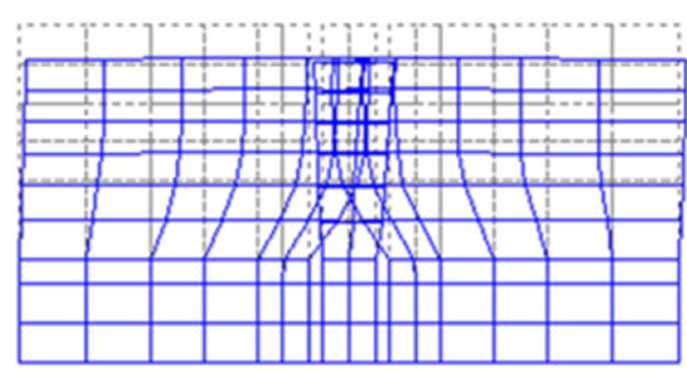

a Deformation of surrounding ground when pullout holes are hollow

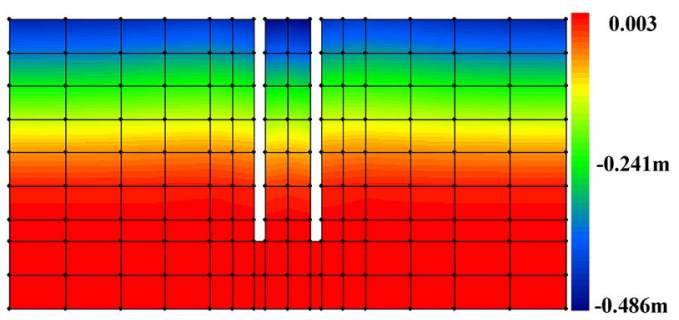

b Y-direction settlement contour when pullout holes are hollow

Fig. 1 Deformation behavior of surrounding ground in 2D analysis [6]. a Deformation of surrounding ground when pullout holes are hollow. b Y-direction settlement contour when pullout holes are hollow 


\section{Failure condition}

When the ground fails, shear deformation is concentrated in a limited area and a slip surface is generated. This slip surface is generated before the failure and gradually grows into a large-scale slip [2]. In addition, during the formation of pullout holes, it is thought that the settlement spreads into a circle if the ground is isotropic. Therefore, the authors used Drucker-Prager failure criteria to handle the ground which is of a frictional material.

This Drucker-Prager model uses yield function ${ }^{t} f_{D P}$ as defined by Eq. (1).

$$
{ }^{t} \boldsymbol{f}_{D P}=\alpha^{t} \boldsymbol{J}_{1}+\sqrt{{ }^{\boldsymbol{t}} \boldsymbol{J}_{2 D}}-\kappa
$$

where, ${ }^{t} J_{1}$ is the first invariant of stress and ${ }^{t} J_{2 D}$ is the second invariant of deviatoric stress.

Material constant $\alpha$ and material parameter $\kappa$ are obtained from Eqs. (2) and (3).

$$
\begin{aligned}
& \alpha=\frac{2 \sin \phi}{\sqrt{3}(3-\sin \phi)} \\
& \kappa=\frac{6 \cos \phi}{\sqrt{3}(3-\sin \phi)}
\end{aligned}
$$

where, $\phi$ is the internal friction angle and $c$ is the adhesion coefficient.

\section{Analysis flow}

In this study, two types of initial stress analysis and static total stress analysis were carried out. The convergence calculation uses the Newton-Rapson method with Eq. (4).

$$
\left[K_{i}^{T}\right]\left\{\Delta u_{i}\right\}=\left\{F^{a}\right\}-\left\{F_{i}^{n r}\right\}
$$

where, $\left[K_{i}^{T}\right]$ is a tangent stiffness matrix, $\left\{\Delta u_{i}\right\}$ is a displacement increment vector, $\left\{F^{a}\right\}$ is a load vector, and $\left\{F_{i}^{n r}\right\}$ is a restored load vector calculated from the element stress.

\section{Setting the initial conditions}

Set the initial conditions of displacement. The total displacement increment can be obtained by the sum of the displacement increment of each step [see Eqs. (5) and (6)].

$$
\begin{aligned}
& \boldsymbol{u}_{\boldsymbol{i}}=0 \\
& \Delta \boldsymbol{u}_{\boldsymbol{i}}=\sum \delta u
\end{aligned}
$$

where, $u_{i}$ is the displacement and $\Delta u_{i}$ is the total displacement increment.

\section{Calculation of strain and strain increment}

From the displacement and the displacement increment obtained in the previous step (a), strain $\varepsilon_{i}$ and strain increment $\Delta \varepsilon_{i}$ can be obtained by Eqs. (7) and (8).

$$
\begin{aligned}
& \boldsymbol{\varepsilon}_{\boldsymbol{i}}=B \boldsymbol{u}_{\boldsymbol{i}} \\
& \Delta \boldsymbol{\varepsilon}_{\boldsymbol{i}}=B \Delta \boldsymbol{u}_{\boldsymbol{i}}
\end{aligned}
$$


where, $B$ is a matrix that gives the relation between the strain component in the element and the nodal displacement.

\section{Calculate stress $\sigma_{i}^{\prime}$ and stress increment $\Delta \sigma_{i}^{\prime}$ using constitutive law}

From the strain increment determined by Eq. (7), the stress and stress increment at the Gaussian point of each element are determined by Eqs. (9) and (10).

$$
\begin{aligned}
& \Delta \sigma_{i}^{\prime}=D \Delta \boldsymbol{\varepsilon}_{i} \\
& \sigma_{i}^{\prime}=\sigma_{i-1}+\Delta \sigma_{i}^{\prime}
\end{aligned}
$$

where, $D$ is a function of stress and strain (configuration matrix). If stress increment $\Delta \sigma_{i}^{\prime}$ does not exceed the Drucker-Prager equation (see Eq. (1)), the element determines the elastic shape. If stress increment $\Delta \sigma_{i}^{\prime}$ satisfies or exceeds the Drucker-Prager equation (see Eq. (1)), the element is judged to be in an elasto-plastic state.

\section{Calculation of restored load vector (external force vector)}

As the stress state cannot exceed the Drucker-Prager equation (see Eq. (1)), the stress is corrected to satisfy the Drucker-Prager equation (see Eq. (1)) for that element. From this corrected stress, the restored load vector $\left\{F_{i}^{n r}\right\}$ is calculated.

\section{Calculation of load vector}

The load vector equivalent to the stress determined by Eq. (9), that is, the internal force vector, is determined by Eq. (11).

$$
\left\{\boldsymbol{F}^{a}\right\}=\boldsymbol{B}^{T} \sigma_{i}^{\prime}
$$

In the case of the initial stress analysis, this load vector corresponds to its own weight.

\section{Calculation of residuals}

The difference between the internal force vector and the external force vector is determined by Eq. (12).

$$
\left[\boldsymbol{K}_{i}^{T}\right]=\left\{\boldsymbol{F}^{a}\right\}-\left\{\boldsymbol{F}_{i}^{n r}\right\}
$$

where, $\left\{F^{a}\right\}-\left\{F_{i}^{n r}\right\}$ is the residual vector.

\section{Calculation of approximate displacement vector $u_{i+1}$}

The approximate displacement vector is obtained by the sum of the displacement obtained by Eq. (5) and the displacement increment obtained by Eq. (6) according to Eq. (13).

$$
u_{i+1}=u_{i}+\Delta u_{i}
$$

\section{Determination of residual convergence}

If the residual obtained by Eq. (12) falls within the specified convergence criteria, it is regarded as having converged, and the process proceeds to (i). If the residual obtained by 
Eq. (12) does not fall within the range of the convergence criterion, the process returns to (b) and the calculation is continued to (h) again. If this iteration does not enable the residual to fit within the convergence criteria, it is regarded as having diverged and the result is not output.

\section{End the repeated calculation and output the result}

Formation of pullout holes After the repeated calculation on the original ground before the pullout holes form, the parts of the pullout holes and the surrounding ground are virtually separated and calculated. That is, it is assumed that a force (an external force equivalent to an excavation) acting around the pullout holes, before the formation of the pullout holes, is applied to the surrounding ground as an external force.

Filler injection Filler injection is repeated from (b) to (i) until the weight of the filler acts on the surrounding ground by the injection of the filler after the formation of pullout holes. Equations (14) and (15) show the stress equation that acts on the surrounding ground when the filler is injected into the pullout holes.

$$
\begin{aligned}
& \sigma_{z}=\gamma z \\
& \sigma_{x}=\sigma_{z}=\gamma z K_{0}
\end{aligned}
$$

where, $\sigma_{z}$ is the weight of the filler acting in the depth direction, $\sigma_{x}$ and $\sigma_{z}$ are the stress acting in the horizontal direction by the filler, $z$ is the depth at which the filler is injected, $\gamma$ is the unit weight of the filler, and $K_{0}$ is the lateral soil and a pressure coefficient.

\section{Analysis of cross section}

Most cities in Japan are located on soft ground; and therefore, many foundation piles are supporting structures by being installed up to the supporting layer. In the present analysis, therefore, in order to assume that a soft clay layer (assumed as the soft ground) is located on a strong sand gravel layer (assumed as the supporting layer), the cross section is set to be composed of two layers. The upper layer is the soft layer; the clay has an $\mathrm{N}$-value of approximately 2 and a thickness of $18 \mathrm{~m}$. The lower layer, the supporting layer, is made of a sand gravel layer with an $\mathrm{N}$-value of approximately 50 and a layer thickness of $8 \mathrm{~m}$. In addition, the width of the cross section is set to be $50 \mathrm{~m}$ (X-direction), the depth is set to be $50 \mathrm{~m}$ (Z-direction), and the depth of the cross section is set to be $26 \mathrm{~m}$ (Y-direction), so as not to be affected by the boundary conditions.

For the arrangement of the pullout holes, in order to evaluate the mutual influence of the pullout holes, the number of holes is set to two, three, and four. The diameter of each pullout hole is set to $2 \mathrm{~m}$, and the interval is set to be $2 \mathrm{~m}$. In addition, the depth of the pullout holes is set to be $20 \mathrm{~m}$, that is, the penetration depth to the supporting layer is $2 \mathrm{~m}$.

For the mesh division, the accuracy is improved by reducing the mesh spacing near the pullout holes. In addition, even when the pullout holes are filled, the mesh is made finer in order to determine the behavior of the filled portion of the pullout holes. As the 
boundary conditions, the bottom is a fixed fulcrum and the lateral boundary is a vertical roller fulcrum.

In the analysis, the authors compare the ground settlement when pullout holes do not exist, when the pullout holes are left hollow, and when the pullout holes are filled with a filler.

The analysis mesh and the analysis cross section are shown in Fig. 2. It is also shown in Fig. 2 that the red border is the part where pullout holes formed and the yellow line is the boundary between the clay layer and the sand gravel layer. The size of each element shown in Fig. 3 is determined as a result of a preliminary study.

\section{Material parameters}

Table 1 shows the element parameters used in the analysis, Table 2 shows the parameters related to the ground, and Table 3 shows the parameters for the filler. In this analysis, the authors use a fluidization-treated soil for which there is a great deal of experimental data on this soil as a filler $[4,12]$. In order to evaluate the influence of the filler strength on the ground, an analysis of three types of filler is carried out by changing the parameters of the fluidization-treated soil. From the ones with small strength, the authors chose filler (i), filler (ii), and filler (iii). The parameters used for the analysis were determined with reference to the existing literature, as shown in Eq. (16) [4].

$$
\mathrm{E}=1128.3 \mathrm{q}_{\mathrm{u}}+23393
$$

where, $\mathrm{E}\left(\mathrm{kN} / \mathrm{m}^{2}\right)$ is the elastic modulus, $v(-)$ is Poisson's ratio, $\gamma_{t}\left(\mathrm{kN} / \mathrm{m}^{3}\right)$ is the unit volume weight of the soil, $S_{u}\left(\mathrm{kN} / \mathrm{m}^{2}\right)$ is the shear strength of the soil, $\phi\left(^{\circ}\right)$ is the internal friction angle, and $q_{u}\left(\mathrm{~N} / \mathrm{mm}^{2}\right)$ is the compressive strength.

\section{Influence of condition of pullout holes on surrounding ground}

In this study, the displacement and principal stress distribution in the surrounding ground were compared when pullout holes do not exist, when the pullout holes are left hollow, and when the pullout holes are filled with the filler.

\section{Mutual influence of pullout holes when leaving pullout holes hollow}

Figure 3 shows the contours of the settlement and the deformation when two pullout holes exist and they are left hollow. From this, the maximum settlement on the ground surface was $0.15 \mathrm{~m}$. In addition, the region up to $\pm 15 \mathrm{~m}$ in the $\mathrm{X}$ direction and the region of $-14 \mathrm{~m}$ to $16 \mathrm{~m}$ in the $\mathrm{Z}$ direction were affected by the settlement on the ground surface; and conversely, a bulge was generated outside the affected region. This was caused by downward force due to the self-weight of the ground acting by the initial stress analysis, while upward force was exerted because downward force was released by the formation of pullout holes. As a result, it is thought that a bulge was generated in the region away from the pullout holes. According to the contour of the settlement shown in Fig. 3, the settlement on the ground surface spread elliptically around the pullout holes, and it gradually approached a circle as it separated from the pullout holes. In addition, the largest settlement was generated in the part between the pullout holes. From the deformation shown in Fig. 3, a force worked in 


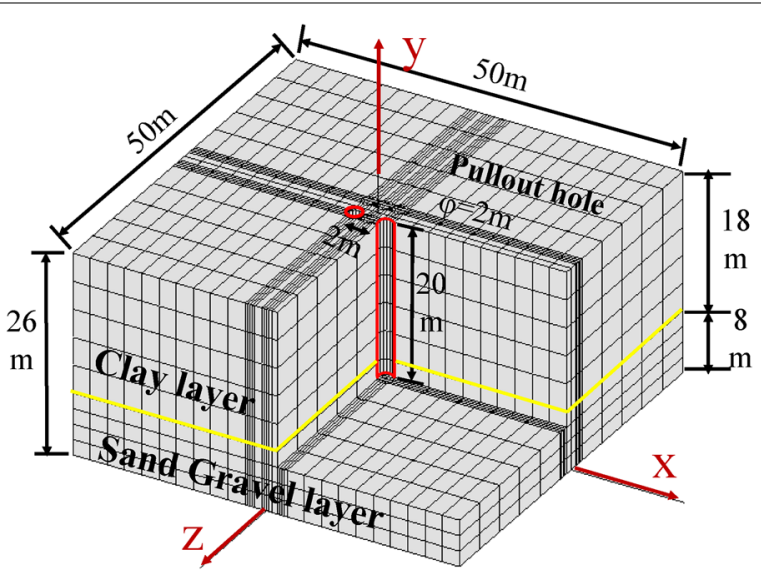

a In the case of two pullout holes

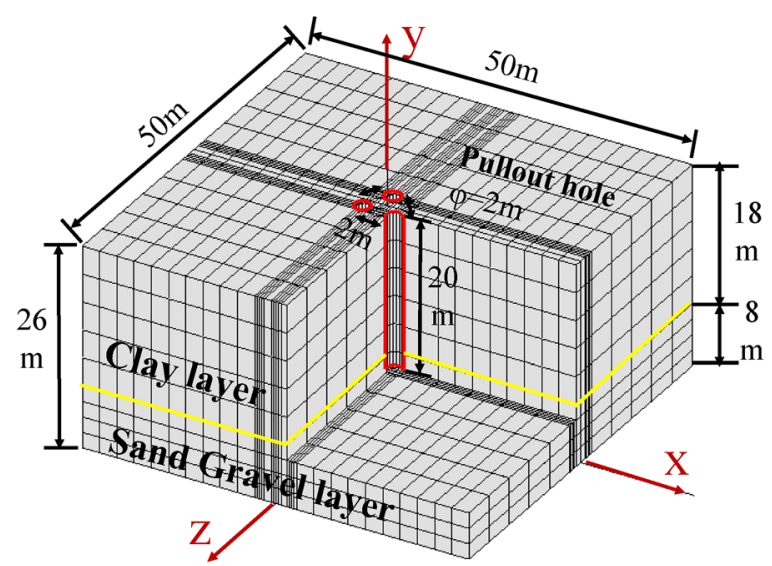

b In the case of three pullout holes

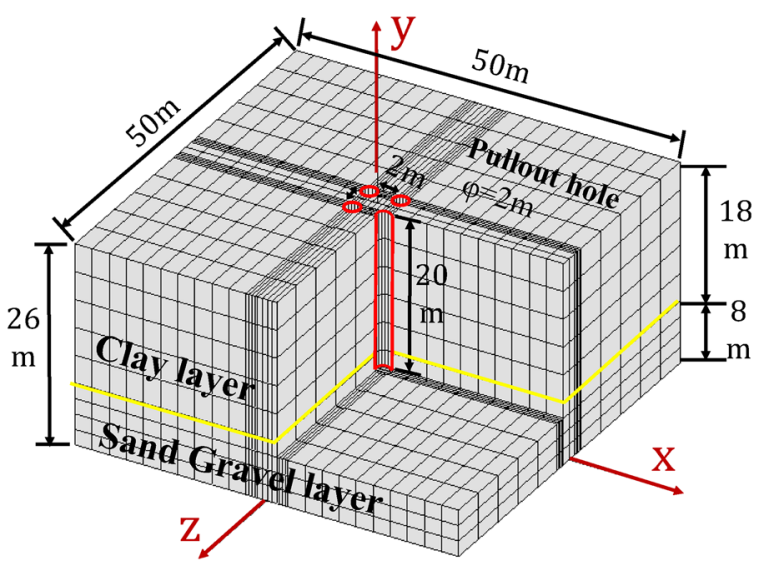

c In the case of four pullout holes

Fig. 2 Analysis section for ground and pullout holes. a In the case of two pullout holes. $\mathbf{b}$ In the case of three pullout holes. $\mathbf{c}$ In the case of four pullout holes 


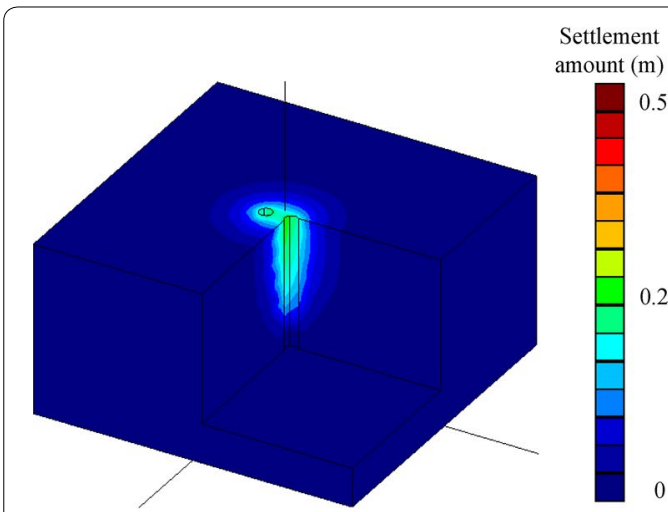

a Settlement contour map

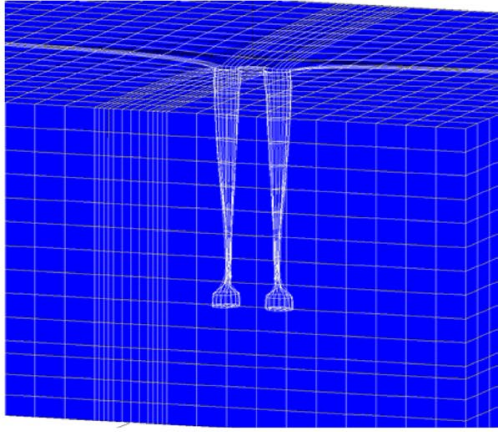

b Deformation

Fig. 3 Deformation behavior of surrounding ground when two pullout holes are hollow. a Settlement contour map. b Deformation

Table 1 Element parameters for ground and filler

\begin{tabular}{lllc}
\hline & Clay layer & Sand gravel layer & Filler \\
\hline$\gamma_{t}\left(\mathrm{kN} / \mathrm{m}^{2}\right)$ & 14 & 19 & 15 \\
Failure criteria & Drucker-Prager failure criteria & & \\
\hline
\end{tabular}

Table 2 Ground parameters

\begin{tabular}{lll}
\hline & Clay layer & Sand gravel layer \\
\hline$E\left(\mathrm{kN} / \mathrm{m}^{2}\right)$ & 7900 & 140,000 \\
$V(-)$ & 0.45 & 0.35 \\
$S_{u}\left(\mathrm{kN} / \mathrm{m}^{3}\right)$ & 37.8 & 152.9 \\
$\varphi\left({ }^{\circ}\right)$ & 0 & 42.3 \\
\hline
\end{tabular}

Table 3 Filler parameters

\begin{tabular}{llll}
\hline & Filler (i) & Filler (ii) & Filler (iii) \\
\hline$q_{u}\left(\mathrm{~N} / \mathrm{mm}^{2}\right)$ & 0.1 & 0.5 & 1.0 \\
$E\left(\mathrm{kN} / \mathrm{m}^{2}\right)$ & $1.36 \times 10^{5}$ & $5.88 \times 10^{5}$ & $11.5 \times 10^{5}$ \\
$v(-)$ & 0.48 & 0.48 & 0.48 \\
$S_{u}\left(\mathrm{kN} / \mathrm{m}^{3}\right)$ & 38.3 & 182.3 & 362.2 \\
$\varphi\left({ }^{\circ}\right)$ & 26.0 & 39.5 & 49.6 \\
\hline
\end{tabular}

the direction of the compression of the pullout holes in the lower part of the clay layer. When the lower part of the piles was compressed, the pullout holes came close to each other. From the above, it can be concluded that when there are two pullout holes, compression by the clay layer of the part sandwiched by the pullout holes and the outer clay layer is received. Therefore, the pullout holes are deformed and affect the settlement of the ground surface. 
Figure 4 shows the contours of the settlement and the deformation when three pullout holes exist and they are hollow. The maximum settlement at the ground surface was $0.31 \mathrm{~m}$. The region influenced by the settlement was up to $\pm 15 \mathrm{~m}$ in the $\mathrm{X}$ direction, from $-14 \mathrm{~m}$ to $16 \mathrm{~m}$ in the $\mathrm{Z}$ direction, and out of the region of influence, as in the case of two pullout holes, and a bump was generated. From the contour of the settlement shown in Fig. 4, the settlement was the largest among the three pullout holes. In addition, although the ground around the pullout holes spread in a triangular shape, it gradually approached a circle. From the deformation shown in Fig. 4, the upper part of the pullout holes was greatly deformed. In the case of two pullout holes, the lower part of the clay layer failed and the holes were deformed so that they came close to each other. In the case of three pullout holes, however, the lower part of the clay layer around the pullout holes was deformed only a little without collapsing. In addition, the inner part of the pullout holes experienced a large settlement compared with the outer side, and the height difference of the wall was deviated and deformed in each pullout hole. The region influenced by the settlement was the same as in the case of two pullout holes. That is, although the settlement was increasing, the region of influence did not change. Therefore, it can be concluded that one additional pullout hole has the most influence on the settlement between each pullout hole, and there is no influence of generating settlement in the surrounding ground.

Figure 5 shows the contours of the settlement and the deformation when four pullout holes exist and they are hollow. The maximum settlement at the surface was $0.35 \mathrm{~m}$. The region influenced by the settlement was up to $\pm 15 \mathrm{~m}$ in the $\mathrm{X}$ direction and $\pm 16 \mathrm{~m}$ in the $\mathrm{Z}$ direction, and out of the region of influence, and the same ridges were generated as in the cases of two and three pullout holes. From the contour of the settlement shown in Fig. 5, the settlement was the largest among the four pullout holes. The settlement expanded like a rhombus in the ground around the pullout holes, but gradually approached a circle. From the deformation shown in Fig. 5, the lower part of the clay layer around the pullout holes became thinner and deformed so as to be concentrated at the center. The region influenced by the settlement was wider than in the case of two and three pullout holes. It is thought that the differences in settlement having an influence

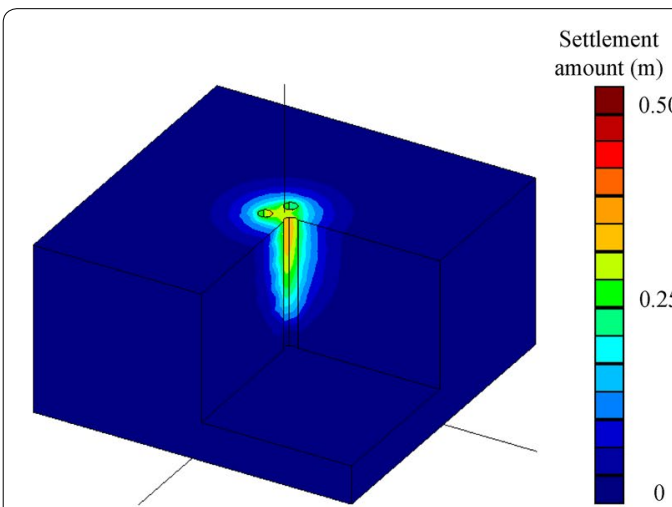

a Settlement contour map

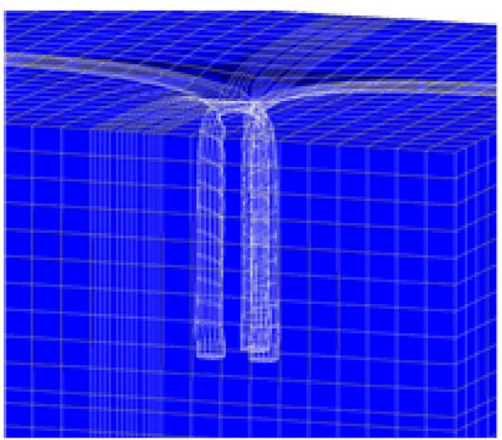

b Deformation

Fig. 4 Deformation behavior of surrounding ground when three pullout holes are hollow. a Settlement contour map. b Deformation 


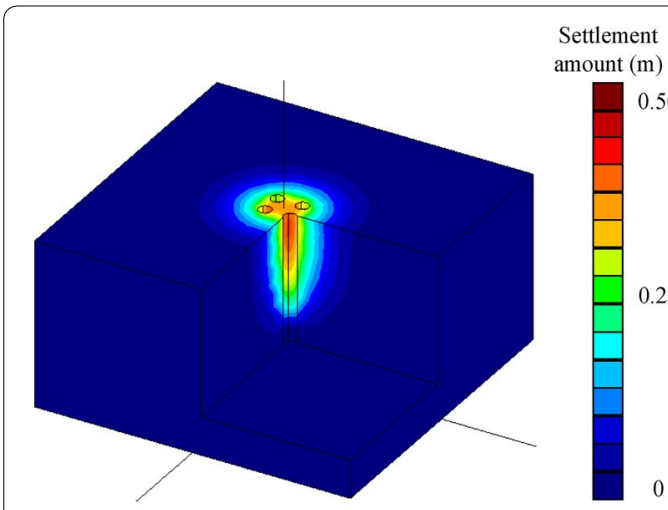

a Settlement contour map

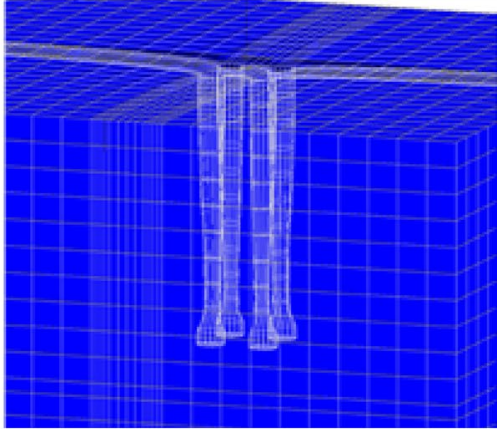

b Deformation

Fig. 5 Deformation behavior of surrounding ground when four pullout holes are hollow. a Settlement contour map. b Deformation

on the surrounding ground are caused by the number of pullout holes becoming an even number.

\section{Injecting filler into three pullout holes}

Figures 6 and 7 show the contours of the settlement and the settlement on the ground surface, respectively, when three pullout holes are filled. When filled with filler (i), the maximum settlement on the surface was $0.008 \mathrm{~m}$. The region influenced by the settlement was $\pm 10 \mathrm{~m}$ in the $\mathrm{X}$ direction and $-9 \mathrm{~m}$ to $12 \mathrm{~m}$ in the $\mathrm{Z}$ direction. When filled with filler (ii), the maximum settlement on the ground was $0.006 \mathrm{~m}$. The region influenced by the settlement was $\pm 10 \mathrm{~m}$ in the $\mathrm{X}$ direction and $-7 \mathrm{~m}$ to $9.5 \mathrm{~m}$ in the $\mathrm{Z}$ direction. When filled with filler (iii), the maximum settlement on the ground was $0.003 \mathrm{~m}$. The region influenced by the settlement was $\pm 10 \mathrm{~m}$ in the $X$ direction and $-7 \mathrm{~m}$ to $9.5 \mathrm{~m}$ in the $\mathrm{Z}$ direction. From the contours of the settlement shown in Fig. 6, the settlement was greatly reduced when the filler was filled, compared to the case where the pullout holes were left hollow. Therefore, it is thought that the settlement phenomenon is suppressed by the filling of the pullout holes. Moreover, when fillers (i), (ii), and (iii) are compared with the settlement, the settlement becomes smaller as the strength of the filler becomes larger. Comparing the region influenced by the settlement with fillers (i), (ii), and (iii), the region influenced by the settlement becomes narrower as the strength of the filler becomes larger. In addition, when filling pullout holes, the complete settlement of the filler to the deepest part of the holes is essential because settlement is also generated in the supporting layer (sand gravel layer). However, with filler (i), the settlement is locally large in the filler portion (see Fig. 7). On the other hand, fillers (ii) and (iii) have the same settlement behavior as the surrounding ground. Therefore, it is considered that the compressive stress from the surrounding ground greatly acts on the filler portion because the strength of the filler is insufficient. From the above, it is clear that the strength of the filler must be adjusted in order to adapt to the surrounding ground and the condition of the pullout holes. 


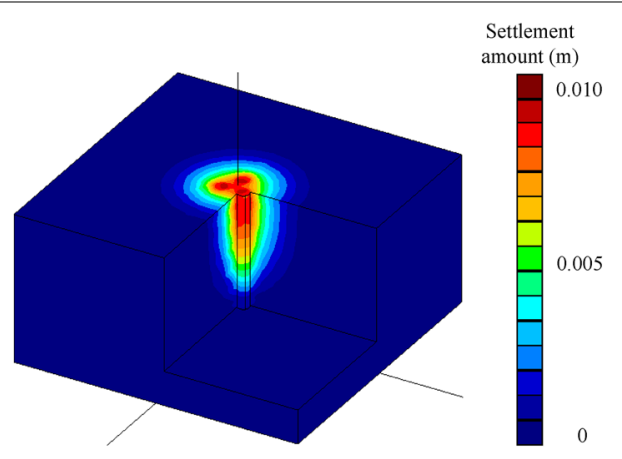

a Filler (i)

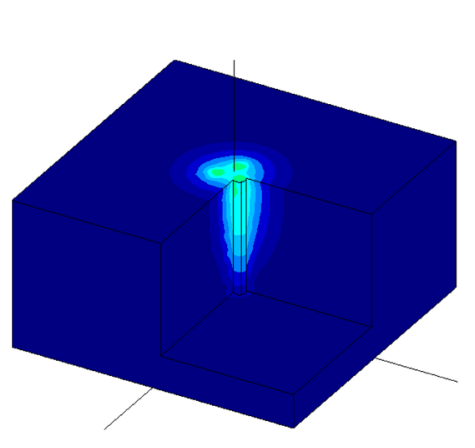

b Filler (ii)
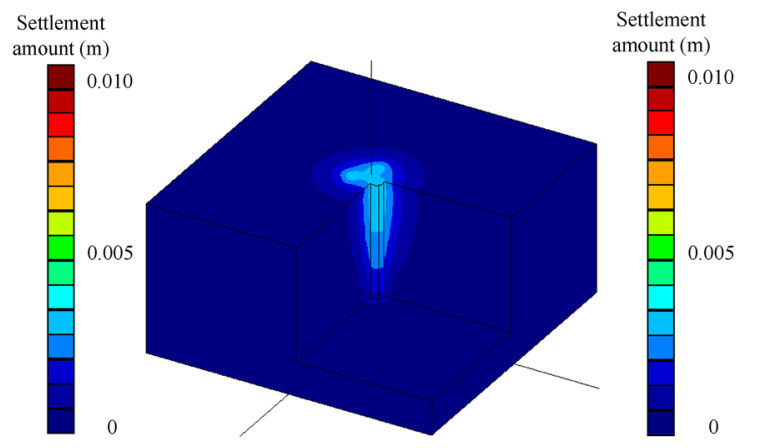

Fig. 6 Settlement of surrounding ground when pullout holes are filled. a Filler (i). b Filler (ii). c Filler (iii)

c Filler (iii)

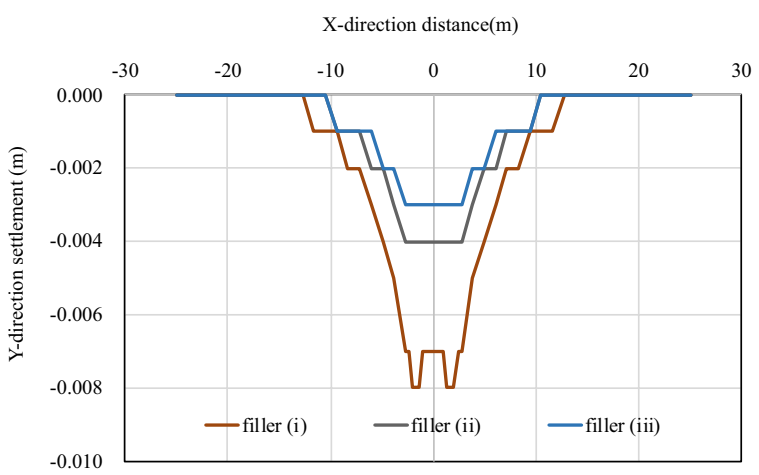

Fig. 7 Y-direction settlement on ground surface with fillers (i), (ii) and (iii)

\section{Comparison between hollow and filled pullout holes}

Figure 8 shows a distribution (XY plane view) in which the principal stress is vectordisplayed when three pullout holes are hollow and when three pullout holes are filled. In the case of pullout holes, the principal stress is concentrated around the pullout 
holes, and the compressive stress is maximized at the bottom of the pullout holes. This is thought to be due to the stress from the surrounding ground concentrated on the pullout holes by forming pullout holes. When the pullout holes are filled, compressive stress is applied to the pullout holes, but the compressive stress is smaller than when the pullout holes are hollow. This shows that filling the pullout holes can prevent the concentration of stress on the pullout holes. Also, a very large compressive stress is acting at the bottom, because the boundary condition at the bottom is fixed, therefore, the stress is acting upward due to the formation of pullout holes. Similarly, it is thought that the stress from the upper part acts by filling the pullout holes, and the force from the upper and lower parts acts. On the other hand, when the pullout holes are hollow, it is clearly shown that the stress is maximum at the bottom of the pullout holes. However, the concentration of stress on the bottom of the pullout holes can be dispersed by filling from the deepest part of the pullout holes. From the above, the importance of filling in the pullout holes exactly is clarified.

\section{Influence of arrangement of pullout holes on surrounding ground}

It was found that the existence of multiple pullout holes mutually affects each other, and that the settlement becomes larger as the number of holes increases. However, the region influenced by the settlement on the ground surface does not change when the number of pullout holes increases from two to three, but does change when the number increases from three to four. As a result, the region of settlement does not increase as the

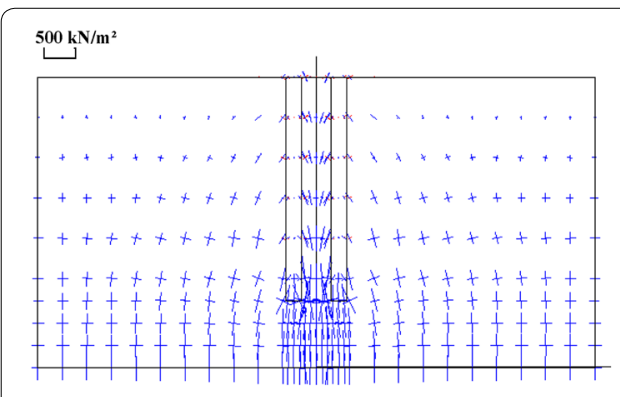

a When three pullout holes are hollow

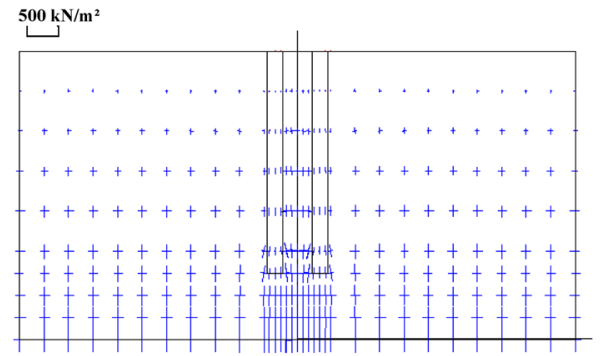

c When three pullout holes are filled with filler (ii)

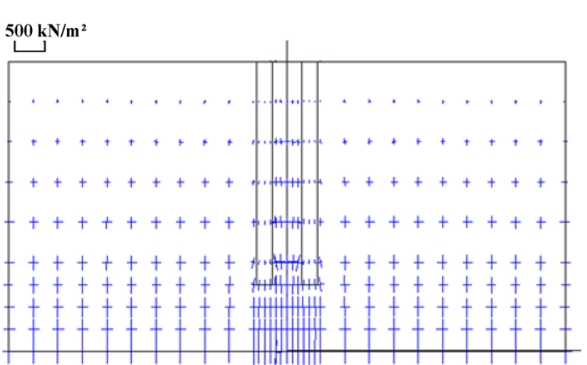

b When three pullout holes are filled with filler (i)

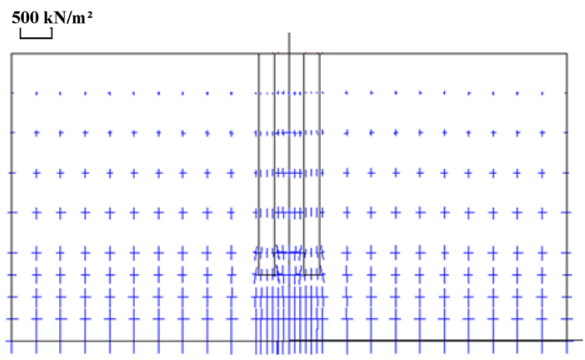

d When three pullout holes are filled with filler (iii) Fig. 8 Principal stress of surrounding ground when pullout holes are hollow and filled. a When three pullout holes are hollow. b When three pullout holes are filled with filler (i). c When three pullout holes are filled with filler (ii). $\mathbf{d}$ When three pullout holes are filled with filler (iii) 
number of pullout holes increases. This is considered to be influenced by the spread of settlement on the ground surface. The spread of settlement within the ground was radial, but the extent of the influence of the settlement on the ground surface was circular. That is, because the settlement spreads isotropically outside the pullout holes, it is thought that it does not affect the region influenced by the settlement if it is not arranged symmetrically. In addition, in the case of two and four pullout holes, local deformation is generated in the clay layer, but in the case of three pullout holes, the local deformation on the ground surface is comparably large. From this, when pullout holes are arranged symmetrically, large deformation is generated in the clay layer, and the region influenced by the settlement expands. In other words, if existing piles are arranged symmetrically, there is a risk that the region influenced by the settlement may extend due to the pulling out of the piles, as predicted by the rule of thumb, which may also cause unequal settlements to the surrounding ground and nearby structures. Caution is advised in such cases.

As can be understood from the allowable settlements for the foundation types shown in Table 4 (Akishige et al. [1], the allowable settlement varies depending on the foundation used. These analysis results are applicable to the allowable settlement of all foundations, but the results may exceed the allowable settlement of all foundations if the number of pullout holes increases. It is important to have advance knowledge of the behavior of each case by analysis, so as not to use a filler with a level of strength which may cause local settlement, such as filler (i), as shown in Fig. 6.

\section{Conclusions}

In order to evaluate the influence of pullout holes on the static physical characteristics of the surrounding ground, an elasto-plastic analysis was performed using a three-dimensional static FEM.

The results obtained from the analysis are as follows.

1. When pullout holes are left hollow, a large settlement is generated in the vicinity of the holes. In particular, the settlement is generated largely in the region surrounding the pullout holes.

2. As the number of pullout holes increases, the settlement of the surrounding ground increases. However, the region influenced by the settlement does not change when the number of existing piles pulled out goes from two to three, although it expands when the number goes from three to four. This is because when the arrangement of pullout holes is two or four, the compressive force acts from the ground sandwiched by the pullout holes and the ground outside the pullout holes. It is thought that the

Table 4 Allowable settlements by foundations in the ground

\begin{tabular}{lccc}
\hline & Individual footing & Continuous footing & $\begin{array}{c}\text { Raft } \\
\text { foundation }\end{array}$ \\
\hline Relative settlement $(\mathrm{cm})$ & 3 & 4 & 5 \\
Maximum settlement $(\mathrm{cm})$ & 10 & 20 & 25 \\
\hline
\end{tabular}


clay layer near the piles has failed. That is, when there is an even number of existing piles, an unequal settlement of the surrounding ground is generated.

3. By filling the pullout holes, the authors were able to make the settlement smaller. In addition, the region influenced by the settlement became narrower when the pullout holes were filled compared with the case of hollow pullout holes. Therefore, filling pullout holes with a filler is an effective method of ground improvement for reducing ground settlement.

4. When filling the pullout holes with a filler, it was found that the displacement of the surrounding ground became smaller as the strength of the filler increased. In addition, comparing filler (i) with fillers (ii) and (iii), the region influenced by the settlement was narrow. And, as the strength of the filler increased, the region of influence became narrower, but it was not a proportional relationship.

5. In the case of filling the pullout holes with the filler with the strength of $0.1 \mathrm{~N} / \mathrm{mm}^{2}$, the settlement was locally large in the filler portion. However, when the strength of the filler was $0.5 \mathrm{~N} / \mathrm{mm}^{2}$ or $1.0 \mathrm{~N} / \mathrm{mm}^{2}$, the behavior was the same as the surrounding ground. Therefore, it is considered that the filler strength should be appropriate depending on the surrounding ground and the condition of the pullout holes.

6. When pullout holes remain hollow, stress concentrates at the bottom of the holes. However, by filling the pullout holes, it is possible to reduce the stress concentrating around and at the bottom of the pullout holes. Thus, it is essential to completely fill in the filler to the deepest part of the pullout holes.

The authors have not studied the influence of the difference in the arrangement intervals or the shapes of pullout holes, the number of holes, and the difference in the parameters of the surrounding ground. In a future work, it will be necessary to perform analyses that vary these conditions and to obtain the characteristics of the fillers that are applied. In addition, the authors will create pullout holes which reflect more closely the situation in the field.

\section{Authors' contributions}

In order to evaluate the influence of pullout holes on the static physical characteristics of the surrounding ground, SK and SI carried out an elasto-plastic analysis using a three-dimensional static FEM, SI drafted this manuscript. AJ and SC gave valuable suggestions and correction. All authors read and approved the final manuscript.

\section{Competing interests}

The authors declare that they have no competing interests.

\section{Author details}

Japan Association for Pulling-out Existing Piles, Tokyo, Japan. ${ }^{2}$ Department of Civil Engineering, Shibaura Institute

of Technology, Tokyo, Japan. ${ }^{3}$ Faculty of Engineering, Kasetsart University, Bangkok, Thailand.

Received: 14 April 2019 Accepted: 2 June 2020

Published online: 09 July 2020

\section{References}

1. Akishige H, Tamura M, Watanabe K, Kimura T, Nemoto H, Kaneko O, Mizutani Y, Abe A (2004) Performance evaluation method of foundation in building regulations of Japan and oversea (Part 1: Limitations of settlement), Summaries of Technical Papers of Annual Meeting, Architectural Institute of Japan, 621-622

2. Aydin A, Johnson A (1978) Development of faults as zones of deformation bands and as slip surfaces in sandstone. Pure Appl Geophys 116(4-5):931-942 
3. Civil Engineering (2019) What is Pile Foundation? Types of Pile Foundation. https://civiltoday.com/geotechnic al-engineering/foundation-engineering/deep-foundation/176-pile-foundation-definition-types. Accessed $28 \mathrm{Mar}$ 2019

4. Furugaichi Y (2011) Deformation properties of the backfill material which has a fluidity and self-hardening. Town Value-up Manag Report 37:41-44

5. Helical Drilling Inc. (2019) 170 West Broadway. https://www.helicaldrilling.com/case-study/secant-pile-westbroadw ay/. Accessed 27 Mar 2019

6. Inazumi S, Namikawa T, Kuwahara S, Hamaguchi S (2017) Influence of pulling out existing piles on the surrounding ground. Int J GEOMATE 13(35):16-21

7. Jiang M, Jiang T, Crosta G, Shi Z, Chen H (2015) Modeling failure of jointed rock slope with two main joint sets using a novel DEM bond contact model. Eng Geol 193:79-96

8. Kumar N, Dey A (2014) Finite element analysis of flexible anchored sheet pile walls: effect of mode of construction and dewatering. Golden Jubilee Conference of the IGS Bangalore Chapter. Geo-Innovations 1:8

9. Kuwahara S, Inazumi S (2019) Settlement of surrounding grounds due to existence of pile pulling-out holes. Int J GEOMATE 16(54):81-85

10. Kuwahara S, Hamaguchi S, Shimada Y, Inazumi S (2019) Construction theories and examples for method of powerfully chucking the tip of existing pile at removal of existing piles. Jpn Geotechn J 14(1):69-76

11. Mroueh H, Shahrour I (2008) Numerical analysis of the response of battered piles to inclined pullout loads. Int J Numer Anal Meth Geomech 33(10):1277-1288

12. Nakazawa F, Furugaichi Y (2015) Evaluation of Young's modulus of liquidity stabilized soil. Tokyu Constr Tech Rep 40:49-52

13. Profound: Pile Driving Analysis \& Dynamic Load Testing PDA/DLT-Series. https://www.profound.nl/pda-dlt/. Accessed 28 Mar 2019

14. Resare F (2015) Analysis of an inclined pile in settling soil. Master Sci Royal Instit Technol 1:34

15. Saini S, Goyal ET (2019) Analysis of piled raft foundation using MIDAS GTS NX. Int Res J Eng Technol 6(5):5491-5499

16. Yoshioka S, Kawasaki H (2016) Japan's high-growth postwar period (the role of economic plans). ESRI Res Note Cabinet Office 27:1-82

\section{Publisher's Note}

Springer Nature remains neutral with regard to jurisdictional claims in published maps and institutional affiliations.

\section{Submit your manuscript to a SpringerOpen ${ }^{\odot}$ journal and benefit from:}

- Convenient online submission

Rigorous peer review

Open access: articles freely available online

- High visibility within the field

Retaining the copyright to your article

Submit your next manuscript at $\mathbf{s p r i n g e r o p e n . c o m ~}$ 